\title{
Nonlinear Buckling Analysis of Steel Cylindrical Shell with Elliptical Cut-out Subjected to Longitudinal Compressive Load
}

\author{
K. N. Salloomi ${ }^{1 *}$, L. A. Sabri ${ }^{2}$, Y. M. Hamad ${ }^{1}$ and S. Al-Sumaidae ${ }^{3}$ \\ ${ }^{1}$ Department of Automated Manufacturing Engineering, University of Baghdad, \\ Baghdad 10071, Iraq \\ *Email: kareem@kecbu.uobaghdad.edu.iq \\ Phone: +9647906115136 \\ ${ }^{2}$ Department of Mechanical Engineering, Case Western Reserve University, USA \\ ${ }^{3}$ Department of Biomedical Engineering, University of Baghdad, Iraq
}

\begin{abstract}
The current paper investigates the effect of cut-out design parameters on load-bearing capacity and buckling behaviour of steel cylindrical shell using a nonlinear finite element analysis in modelling cylinder buckling under longitudinal compressive load. The effect of four geometry design parameters: shell diameter to thickness ratio, cut-out location, orientation, and size were investigated in this study. To enhance the prediction of buckling behaviour, both geometrical and material nonlinearities were considered. An ANSYS APDL code was written and tested by verifying its validity through comparison with former buckling study. The results showed that changing the cut-out location from midheight of the cylindrical shell towards a fixed edge caused an increase in the buckling load value. Moreover, the study showed that increasing parameters such as shell thickness and cut-out orientation have a positive influence in which the buckling load value increased too. For fast design purposes, an empirical numerical based regression formula was presented for the calculation of the critical buckling load of a cylindrical shell having an elliptical cut-out.
\end{abstract}

Keywords: nonlinear buckling, cylindrical shell, elliptical cut-out, finite element.

\section{INTRODUCTION}

Many structural applications require using cylindrical shells in different shapes to overcome the various types of subjected loads like axial compression, bending and torsion load. Structural specifications such as high load carrying capability and low weight feature contributed highly in the success of using cylindrical shells in many common engineering applications such as missiles and aircraft structures, and in many other industrial applications like pipelines, automobiles, and tanks in addition to recently used in biomechanics field as a biological form such as eye and the skull, plant and animal shapes. The axial compression load is often presented in such applications, and the buckling is the perspective mode of failure. These shells are ordinarily having geometric imperfections such as cut-outs with various shapes and locations which may lead to highstress concentration and play the principal role for increasing the possibility of buckling failure under axial compression Ifayefunmi and Błachut [1]. In literature, many studies were accomplished concerning with the buckling behaviour of the cylindrical shell under axial load with and without geometric imperfections. Hart Smith [2] used serf-consistent theory of thin shells to develop a theoretical study that can solve the problem of the elastic 
buckling of an ideal thin cylindrical shell under uniform axial compression. Sheinman and Simitess [3] and Stasiewicz [4] described a solution procedure for the full structural analysis of a thin cylindrical shell having a geometrical imperfection and loaded axially. The authors studied the structural response characteristics of the considered shell due to changing geometrical parameters like radius to thickness and length to radius ratios. Eggwertz and Samuelson [5] and Lykhachova [6], discussed several problems associated with cut-outs in shells subjected to buckling. The study used simple classical theory, experimental and numerical methods to propose a simple design procedure for the case of cylindrical shells with circular and rectangular cut-outs and subjected to axial compression. Finite element analyses were applied to confirm the presumed stress distribution at the edge of the hole and to clarify the load carrying capacity reduction arisen by the hole. Based on Flugge's linear theory for isotropic circular cylindrical shells, a general buckling solution was derived by Zou and Foster [7]. The study formulated a simple form for buckling loads for moderate length orthotropic cylindrical shells under combined axial compression and external pressure.

Experimental and numerical methods were introduced by Jullien and Liman [8] to explore the stability issue of cylindrical shells having cut-outs. The study used square, rectangular, and circular hole shapes with different dimensions. Besides, the study also included the location and the number of holes, and the results indicate that the buckling load is sensitive to the angle or circumferential size of the cut-out. Ifayefunmi and Fadzullah [9] and Estekanchi and Vafai [10] developed a finite element code capable of generating structural models of cylindrical shells with cracks of varying length and orientation. The study considered the buckling analysis of a circular cylindrical shell subjected to tension and compression loads. Mandal and Calladine [11] presented simple experiments on self-weight buckling of thin small-scale silicone rubber cylindrical shells with open-top and fixed-base. The output of the study was that the buckling heights are proportional to thickness raised to the power of approximately 1.5, compared to 1.0 as in the classical theory. In addition, the non-linear finite-element analysis of self-weight buckling used within this study showed that there is a post-buckling plateau' load corresponding to the experimental buckling loads. Mark et al. [12] investigated the initiation and development of imperfections caused by local differential settlement at the supporting base and their impact on the elastic buckling of a thin cylindrical shell under axial compression. Initially, the shells were considered ideal with ideal support but encountering geometric imperfections and residual stresses. Hilburger and Starnes[13] and F. Taheri-Behrooz et al. [14] utilised the numerical approach to predict the response of thin-walled compression-loaded quasi-isotropic laminated composite cylindrical shells with unreinforced and reinforced square cut-outs.

The effects of cut-out reinforcement orthotropy, size, and thickness on the nonlinear response of the cylindrical shells were calculated. Han et al.[15] studied the effect of square cut-outs on thin and moderately thick cylindrical shell subjected to a compression load. The study investigated the influence of the cut-out size, location, and the shell aspect ratio $(L / D)$ on the pre-buckling, buckling, and post buckling responses of the cylindrical shells. The study obtained numerical results for buckling load using the ANSYS software, which was verified with the experimental results conducted for moderately thick-walled shells. Moreover, the study developed empirical equations based on numerical results, using the least square regression method. Shariati and Rokhi [16] and T. Ghanbari Ghazijahani et al. [17] studied the buckling behaviour of axially loaded thin cylindrical shell with elliptical cut-outs. Shell length-to-diameter, diameter-tothickness ratios, and cut-out position were investigated in their study using finite element 
simulation software ABAQUS. Buckling tests were performed for several specimens, and the results of experiments were compared with their numerical results. Finally, formulas for buckling load based on their numerical and experimental results were presented. A key limitation of this study is that it does not address the effect of cut-out orientation on buckling load while the current study does. In a more recent study, Çelebi et al.[18] investigated the effects of the cut-out size and position on the dynamic failure attributes of carbon-fibre-reinforced-polymer (specifically, IM7/8552) cylindrical shells under pure bending. The findings of this study indicate that smaller cut-out sizes have very little effect on the buckling behaviour of the cylindrical shell except when situated in the maximum compressive area of the shell. Also, for medium to large cut-out sizes in the lower half of the cylinder, local buckling around the cut-out cause failure prior to the classical mode.

In this paper, the finite element method was used to investigate the effect of changing the shape and position design parameters of the elliptical cut-out on the buckling failure of cylindrical shell subjected to a compression load. Four independent and important parameters were studied numerically (shell diameter to thickness ratio, cut-out location, orientation, and size), to obtain the general formula for buckling load as a function of these four parameters.

\section{FINITE ELEMENT MODEL AND NUMERICAL CONSIDERATIONS}

The finite element package ANSYS was used to construct and analyse the effect of elliptical cut-out on the loading capacity and buckling behaviour of cylindrical shells subjected to a compression load.

\section{Shell Geometry and Material Properties}

In this paper the length $(L)$ and the diameter $(D)$ of the cylindrical shell were fixed to the values of $200 \mathrm{~mm}$ and $40 \mathrm{~mm}$ respectively, while changing the values of the shell thickness $(t)$, cut-out major to minor axes ratio $(b / a)$, cut-out orientation $(\theta)$, and cut-out longitudinal location $\left(L_{c}\right)$. Three levels were used for each parameter as listed in Table 1.

Table 1. Selected parameters with different levels.

\begin{tabular}{ccccccc}
\hline \multirow{2}{*}{ Level } & \multicolumn{2}{c}{$\mathrm{D}=40 \mathrm{~mm}$} & & $\mathrm{~b} / \mathrm{a}$ & $\theta($ deg. $)$ & $\mathrm{L}_{\mathrm{c}}(\mathrm{mm})$ \\
\cline { 2 - 3 } & $\mathrm{t}(\mathrm{mm})$ & $\mathrm{D} / \mathrm{t}$ & & $\begin{array}{c}2 \\
(\mathrm{~b}=18, \mathrm{a}=9)\end{array}$ & 0 & $33(0.165 \mathrm{~L})$ \\
1 & 0.5 & 80 & & $\begin{array}{c}1.5 \\
(\mathrm{~b}=13.5, \mathrm{a}=9) \\
1\end{array}$ & 45 & $66(0.33 \mathrm{~L})$ \\
3 & 0.75 & 53.3 & & & 90 & $100(0.5 \mathrm{~L})$ \\
\hline
\end{tabular}

The parameters and their values were selected to make the model more general and to include other parameters extracted from the original parameters. Changing the thickness from level 1 to 3 changed the diameter to thickness ratio (D/t) from 80 to 40 which change the shell from moderately thick to a thin level which is important to be included in the study. Levels of (b/a) ratio include both cut-out size and shape which 
varies from ellipse with variable sizes $(b / a=2$ and 1.5$)$ to circular hole $(b / a=1)$. Level 1 of the hole angle $\left(\theta=0^{\circ}\right)$ locates the hole in horizontal configuration while moving to level 3 configures the hole vertically. Location of the hole with respect to the shell length was measured from the lowest edge of the shell ending to the midpoint. The shape of the shell with the cut-out at different levels is shown in Figure 1.

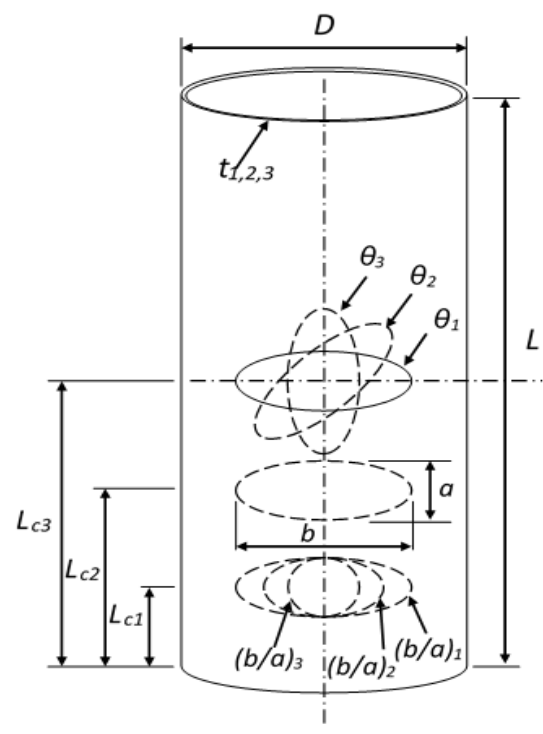

Figure 1 . The geometry of a cylindrical shell with elliptical cut-out.

Models were named according to the sequence of the parameters and their levels. e.g., M1111 means that the parameters are $\mathrm{t}=0.5, \mathrm{~L}_{\mathrm{c}}=33 \mathrm{~mm}, \theta=0^{\circ}$, and $(\mathrm{b} / \mathrm{a})=2$, and all are in level 1. M2323, means that the parameters are $\mathrm{t}=0.75,(\mathrm{~b} / \mathrm{a})=1, \theta=45^{\circ}$, and $\mathrm{L}_{\mathrm{c}}=100 \mathrm{~mm}$. In the current study, a mild steel alloy has been used as a material for the cylindrical shell, and its true stress-strain curve is shown in Figure 2 [16].

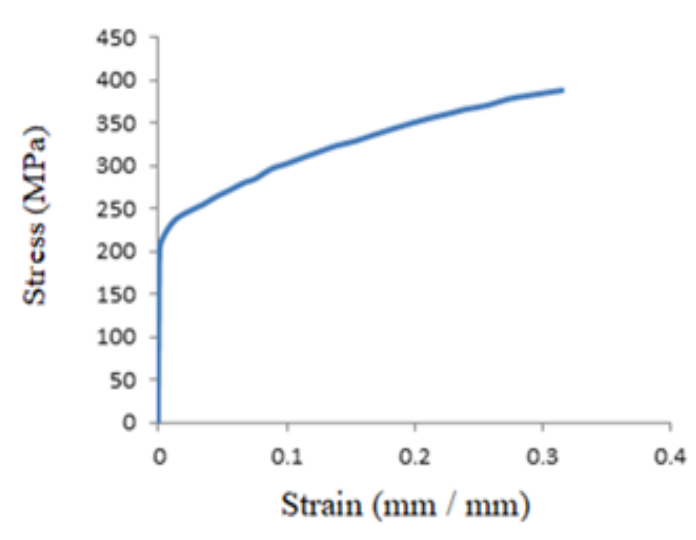

Figure 2. Stress-strain curve of mild steel alloy.

The values of Young's modulus of elasticity $(E)$, yield stress $\left(\sigma_{y}\right)$, and Poisson's ratio (v) are $187.737 \mathrm{GPa}, 212 \mathrm{MPa}$, and 0.33 , respectively. A multi-linear isotropic hardening model has been considered to represent the behaviour of the stress-strain behaviour of mild steel. As we stated above, the Numerical simulation was implemented using the finite element software (ANSYS)[19]. The shell-181 element was used for the 
modelling and analysing of the shell structure. The element is a four-noded element with six degrees of freedom at each node: translations in the $\mathrm{x}, \mathrm{y}$, and $\mathrm{z}$ directions, and rotations about the $\mathrm{x}_{-}, \mathrm{y}_{-}$, and z-axes. Also, it's worthy of mentioning that, the element is suitable to model linear, high rotation, and/or nonlinear strain applications, in addition to analysing thin to moderate thick shell structures as in Han et al.[15]. According to the presence of the cut-outs, no geometrical axisymmetry was existed, so that a complete cylindrical shell was considered in each model when analysing numerical simulation as shown in Figure 3.
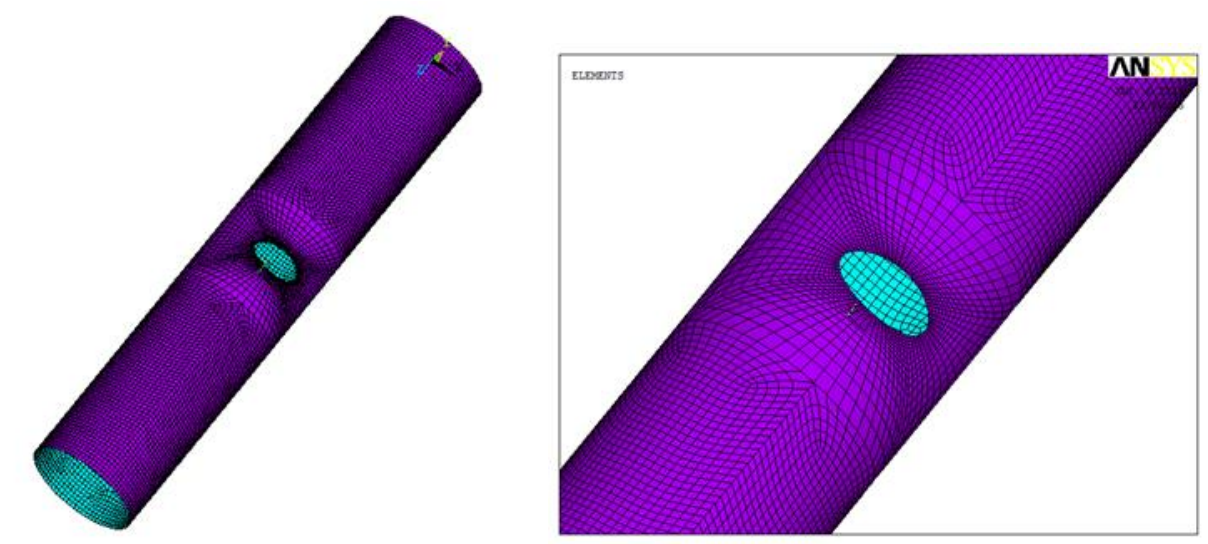

Figure 3. A finite element mesh model of cylindrical shell with cut-out.

\section{Boundary Conditions}

To obtain a realistic buckling response, a $10 \mathrm{~mm}$ displacement along the longitudinal direction was applied to the nodes at the top edge of the cylindrical shell. The $\mathrm{x}$ and $\mathrm{y}$ components of displacement were constrained while keeping the z-component free at the loading edge. Similarly, all six degrees of freedom components in $\mathrm{x}, \mathrm{y}$ and $\mathrm{z}$ directions were restricted to zero value at the bottom edge of the cylindrical edge to asymptote case of the fixed end. To keep uniform displacement in the longitudinal direction, a coupled degree of freedom feature was applied to maintain the plane and circular edge at the loaded end.

\section{Simulation Procedure}

Its worth to mention that the simulation procedure was started first by adopting linear buckling analysis in which the Block Lanczos (ANSYS user's manual) method was applied to predict an approximate estimation of the buckling capacity of the proposed cylindrical shell considered in this study. The analysis returns an overestimated value of buckling load due to non-involvement of geometric nonlinearity. Based on this fact, an APDL ANSYS code was written and executed series of nonlinear analyses to obtain the buckling response. To avoid the occurrence of a singular tangent stiffness matrix, the arc length method was used in the current buckling analyses. The arc-length method helps to avoid bifurcation points and track unloading in case the structure either collapses completely or "snaps through" to another stable configuration. To account for precise buckling behaviour, both geometrical and material nonlinearities were considered in this study. It had been shown that including only the geometrical nonlinearity makes the 
process of tracing the buckling behaviour beyond the peak load so difficult and for that reason, the material nonlinearity was included too as suggested by Han et al.[15].

\section{RESULTS AND DISCUSSION}

The simulation results of the buckling analysis of a cylindrical shell with an elliptical cutout of different sizes in various locations and orientations using the finite element method are explained in this section. An elliptical cut-out with different geometry parameters as explained earlier in table 1 was first created on cylindrical shell geometry of length $200 \mathrm{~mm}$ and diameter of $40 \mathrm{~mm}$. The load was applied in the form of longitudinal displacement as discussed in the boundary conditions section. To verify the results of the present nonlinear numerical procedure, a comparison with the numerical and experimental results obtained by Shariati and Rokhi [16] was conducted. The results listed in Table 2 show a good agreement between the present numerical model with selected experimental and numerical results.

Table 2. Validation of the current proposed model.

\begin{tabular}{cccccccccc}
\hline $\begin{array}{c}\mathrm{D} \\
(\mathrm{mm})\end{array}$ & $\begin{array}{c}\mathrm{L} \\
(\mathrm{mm})\end{array}$ & $\begin{array}{c}\mathrm{t} \\
(\mathrm{mm})\end{array}$ & $\begin{array}{c}\mathrm{L}_{\mathrm{c}} \\
(\mathrm{mm})\end{array}$ & $\begin{array}{c}\theta \\
(\mathrm{deg} .)\end{array}$ & $\begin{array}{c}\mathrm{b} \\
(\mathrm{mm})\end{array}$ & $\begin{array}{c}\mathrm{a} \\
(\mathrm{mm})\end{array}$ & $\begin{array}{c}\text { Buckling } \\
\text { Load (N) } \\
(\text { Present }) \\
\text { Num. }\end{array}$ & $\begin{array}{c}\text { Buckling } \\
\text { Load (N) } \\
{[16]} \\
\text { Num. }\end{array}$ & $\begin{array}{c}\text { Buckling } \\
\text { Load (N) } \\
{[16]} \\
\text { Exp. }\end{array}$ \\
\hline 42.0 & 273 & 0.78 & 191.1 & 0 & 7.96 & 18.25 & 18177.7 & 18181.8 & 17979.1 \\
48.1 & 420 & 0.78 & 210.0 & 0 & 7.94 & 17.54 & 20825.4 & 19828.4 & 19909.4 \\
48.1 & 120 & 0.78 & 60.0 & 0 & 8.04 & 17.75 & 21844.1 & 22177.3 & 21914.0 \\
\hline
\end{tabular}

Having verified the validity of the current proposed numerical model, a series of nonlinear numerical analysis were carried out for the cylindrical shell with elliptical cutouts using the ANSYS program. Four parameters with three levels for each of them were considered which means that $3^{4}$ (i.e. 81) results must be obtained to cover all the possibilities for this system. The obtained results were listed in Table 3, indicating the first buckling load for each conducted model.

Table 3. Levels and corresponding buckling load.

\begin{tabular}{cccccccccccc}
\hline No. & $\mathrm{t}$ & $\mathrm{L}_{\mathrm{c}}$ & $\theta$ & $\mathrm{b} / \mathrm{a}$ & $\begin{array}{c}\text { Buckling } \\
\text { Load (N) }\end{array}$ & No. & $\mathrm{t}$ & $\mathrm{L}_{\mathrm{c}}$ & $\theta$ & $\mathrm{b} / \mathrm{a}$ & $\begin{array}{c}\text { Buckling } \\
\text { Load (N) }\end{array}$ \\
\hline & 1 & 1 & 1 & 1 & 10770.6 & 42 & 2 & 2 & 2 & 3 & 18274.0 \\
2 & 1 & 1 & 1 & 2 & 11314.1 & 43 & 2 & 2 & 3 & 1 & 17773.3 \\
3 & 1 & 1 & 1 & 3 & 11846.4 & 44 & 2 & 2 & 3 & 2 & 17949.1 \\
4 & 1 & 1 & 2 & 1 & 11167.7 & 45 & 2 & 2 & 3 & 3 & 18202.0 \\
5 & 1 & 1 & 2 & 2 & 10866.9 & 46 & 2 & 3 & 1 & 1 & 16766.5 \\
6 & 1 & 1 & 2 & 3 & 11852.6 & 47 & 2 & 3 & 1 & 2 & 17510.9 \\
7 & 1 & 1 & 3 & 1 & 11560.4 & 48 & 2 & 3 & 1 & 3 & 18208.5 \\
8 & 1 & 1 & 3 & 2 & 11477.2 & 49 & 2 & 3 & 2 & 1 & 17289.1 \\
9 & 1 & 1 & 3 & 3 & 11758.1 & 50 & 2 & 3 & 2 & 2 & 17757.7 \\
10 & 1 & 2 & 1 & 1 & 10412.1 & 51 & 2 & 3 & 2 & 3 & 18208.5 \\
11 & 1 & 2 & 1 & 2 & 10889.2 & 52 & 2 & 3 & 3 & 1 & 17739.7 \\
12 & 1 & 2 & 1 & 3 & 11555.8 & 53 & 2 & 3 & 3 & 2 & 17912.0
\end{tabular}




\begin{tabular}{llllllllllll}
13 & 1 & 2 & 2 & 1 & 10753.6 & 54 & 2 & 3 & 3 & 3 & 18208.5 \\
14 & 1 & 2 & 2 & 2 & 11055.6 & 55 & 3 & 1 & 1 & 1 & 23361.2 \\
15 & 1 & 2 & 2 & 3 & 11365.5 & 56 & 3 & 1 & 1 & 2 & 24493.6 \\
16 & 1 & 2 & 3 & 1 & 11320.5 & 57 & 3 & 1 & 1 & 3 & 25570.5 \\
17 & 1 & 2 & 3 & 2 & 11218.8 & 58 & 3 & 1 & 2 & 1 & 24176.5 \\
18 & 1 & 2 & 3 & 3 & 11555.8 & 59 & 3 & 1 & 2 & 2 & 24913.1 \\
19 & 1 & 3 & 1 & 1 & 10539.5 & 60 & 3 & 1 & 2 & 3 & 25570.5 \\
20 & 1 & 3 & 1 & 2 & 11042.9 & 61 & 3 & 1 & 3 & 1 & 24995.3 \\
21 & 1 & 3 & 1 & 3 & 11416.5 & 62 & 3 & 1 & 3 & 2 & 25258.4 \\
22 & 1 & 3 & 2 & 1 & 10881.2 & 63 & 3 & 1 & 3 & 3 & 25570.5 \\
23 & 1 & 3 & 2 & 2 & 11169.3 & 64 & 3 & 2 & 1 & 1 & 23163.4 \\
24 & 1 & 3 & 2 & 3 & 11519.3 & 65 & 3 & 2 & 1 & 2 & 24236.8 \\
25 & 1 & 3 & 3 & 1 & 11197.3 & 66 & 3 & 2 & 1 & 3 & 25323.4 \\
26 & 1 & 3 & 3 & 2 & 11272.6 & 67 & 3 & 2 & 2 & 1 & 23908.9 \\
27 & 1 & 3 & 3 & 3 & 11414.5 & 68 & 3 & 2 & 2 & 2 & 24587.4 \\
28 & 2 & 1 & 1 & 1 & 16800.8 & 69 & 3 & 2 & 2 & 3 & 25323.4 \\
29 & 2 & 1 & 1 & 2 & 17584.3 & 70 & 3 & 2 & 3 & 1 & 24586.7 \\
30 & 2 & 1 & 1 & 3 & 18456.1 & 71 & 3 & 2 & 3 & 2 & 24867.8 \\
31 & 2 & 1 & 2 & 1 & 17408.4 & 72 & 3 & 2 & 3 & 3 & 25281.2 \\
32 & 2 & 1 & 2 & 2 & 17854.9 & 73 & 3 & 3 & 1 & 1 & 23204.1 \\
33 & 2 & 1 & 2 & 3 & 18464.4 & 74 & 3 & 3 & 1 & 2 & 24190.0 \\
34 & 2 & 1 & 3 & 1 & 18018.1 & 75 & 3 & 3 & 1 & 3 & 25196.4 \\
35 & 2 & 1 & 3 & 2 & 18106.0 & 76 & 3 & 3 & 2 & 1 & 23864.6 \\
36 & 2 & 1 & 3 & 3 & 18456.1 & 77 & 3 & 3 & 2 & 2 & 24492.7 \\
37 & 2 & 2 & 1 & 1 & 16670.7 & 78 & 3 & 3 & 2 & 3 & 25196.4 \\
38 & 2 & 2 & 1 & 2 & 17454.2 & 79 & 3 & 3 & 3 & 1 & 24444.4 \\
39 & 2 & 2 & 1 & 3 & 18202.0 & 80 & 3 & 3 & 3 & 2 & 24723.3 \\
40 & 2 & 2 & 2 & 1 & 17235.3 & 81 & 3 & 3 & 3 & 3 & 25196.4 \\
41 & 2 & 2 & 2 & 2 & 17722.3 & & & & & & \\
\hline & & & & & & & & & & \\
\end{tabular}

\section{Load Versus Deformation and Stress State}

Figure 4 illustrates relationship between load and end-shortening for a cylindrical shell of level (1311) i.e parameters are $\mathrm{t}=0.5, \mathrm{~L}_{\mathrm{c}}=100 \mathrm{~mm}, \theta=0^{\circ}$, and (b/a) $=2$ (centrally located cut-out). The front and top views of the deformed cylindrical shell under applied compressive load are shown, and the von-Mises stress contours due to buckling modes at different loading times are also included. It can be shown that the end-shortening curve reaches a critical peak value (threshold) first and then the longitudinal buckling load begins to drop drastically. Before the load reaches its critical peak value, the stress is distributed uniformly through the length of the shell except for around the cut-out region. Then, the stress value increases slightly and the region around the cut-out (in $0^{\circ}$ ) yields first due to the significant amount of deformation that occurs around the cut-out region when the threshold buckling value is attained.

Consequently, the load drops are significant to some specific level and regions near top and bottom ends of the cylindrical shell buckle with a considerable radial deformation which is so clear in part -c- of the response. The contour plot also shows a high amount of radial displacement near the cut-out region indicating a case of global bending and collapse. Here we can deduce that the cylindrical buckling behaviour is similar to the theoretical Euler column buckling behaviour. Figures 5 and 6 show the 
typical behaviour with stress contours of a cylindrical shell with the same parameters described above but with different cut-out orientations $\left(45^{\circ}\right.$ and $\left.90^{\circ}\right)$ i.e. levels 1321 and 1331. The two shells hold the same trend as in the former case of level 1311 in which the end shortening curve increases linearly to its peak value accompanied by small deformation rate that occurs around the cut-out region. The upshot of the load-end shortening curves is that the buckling load capacity of the shell decreases due to cut-out presence. Comparing the contour plot of Figures 4, 5, and 6, it can be deduced that a shell with elliptical cut-out orientated by $45^{\circ}$ experienced the highest level of stress (369.56 $\mathrm{MPa}$ ) around cut-out edges.

Figures 7(a), 7(b) and 7(c) shows the effect of changing shell thickness (t) while keeping the other parameters fixed on load bearing capacity of the proposed cylinder. The end shortening results showed that whether the cut-out position was in the mid-height of the shell or near to the bottom edge, the buckling load increases as the shell thickness increases too and Shariati and Rokhi [16] approved this fact. The results of Table 3 also indicate that the load-bearing capacity is maximum when orientation angle of the cut-out is $90^{\circ}$ which means vertical cut-out has less effect on buckling load capacity compared to cut-out with $0^{\circ}$ and $45^{\circ}$ orientations. The cut-out location is another parameter that affects both buckling load and stress status within the shell. Three different cut-outs along with the height of the shell $(0.165 \mathrm{~L}, 0.33 \mathrm{~L}$, and $0.5 \mathrm{~L})$ were positioned starting from the bottom in which the shell end is fixed totally and going up to the middle height of the shell.

The load-end shortening curves for a compressed cylindrical shell with elliptical cut-out positioned at three different locations are shown in Figures 8 (a), (b) and (c). It can be seen that the curves have conformity points. When the shell buckles, the first conformity point occurs at the buckling point and later, the curves with high $L_{c}$ are above the other curve lines; this indicates the case of load redistribution. The buckling load capacity increases as the level of load redistribution increase too. The results had shown that if the cut-out is positioned in the mid-height of the shell, then the total section around cut-out region yield first leading to a case of global bending which in turn leads to buckling instability. The other case is that if the cut-out is located near the fixed end, then the total section around cut-out yield, causing local buckling around the cut-out.

The results of Table 3 demonstrate that shells with cut-out location close to the shell edge or have lower $L_{c} / L$ ratio had a higher buckling load, and these shells were more resistant to the buckle. For a fixed cut-out height, the results show that an increase in the cut-out ratio b/a caused significant reduction in the buckling load; this fact agrees well with results of references of Fereidoona et al. [20] and Shariati and Rokhi [21]. The results also reveal that for a cylindrical shell with small cut-out size such as the case of levels $(1113,1213$, and 1313), the buckling load capacity increases as a function of cut-out's location. Therefore, the influence of the cut-out location depends highly on its size in which the smaller size cut-outs have less impact on buckling capacity while the opposite is true for larger size cut-outs. The study also showed that increasing cut-out orientation angle would increase buckling load capacity as seen in table 3 . To illustrate more, the buckling load was $10.7706 \mathrm{KN}$ in case of $\mathrm{t}=0.5, L_{c}=33 \mathrm{~mm}, \theta=0^{\circ}$, and $(b / a)=2$, this load was increased to $11.1677 \mathrm{KN}$ in case of $45^{\circ}$ orientation and $11.5604 \mathrm{KN}$ in case of $90^{\circ}$ orientation. This means for cylindrical shells with elliptical cut-out located at $0.165 \mathrm{~L}$, changing cut-out orientations from $0^{\circ}$ to $90^{\circ}$ increased buckling load by $8.6 \%$ and $8.02 \%$ for $0.33 \mathrm{~L}$ and $5.87 \%$ for $0.5 \mathrm{~L}$. 

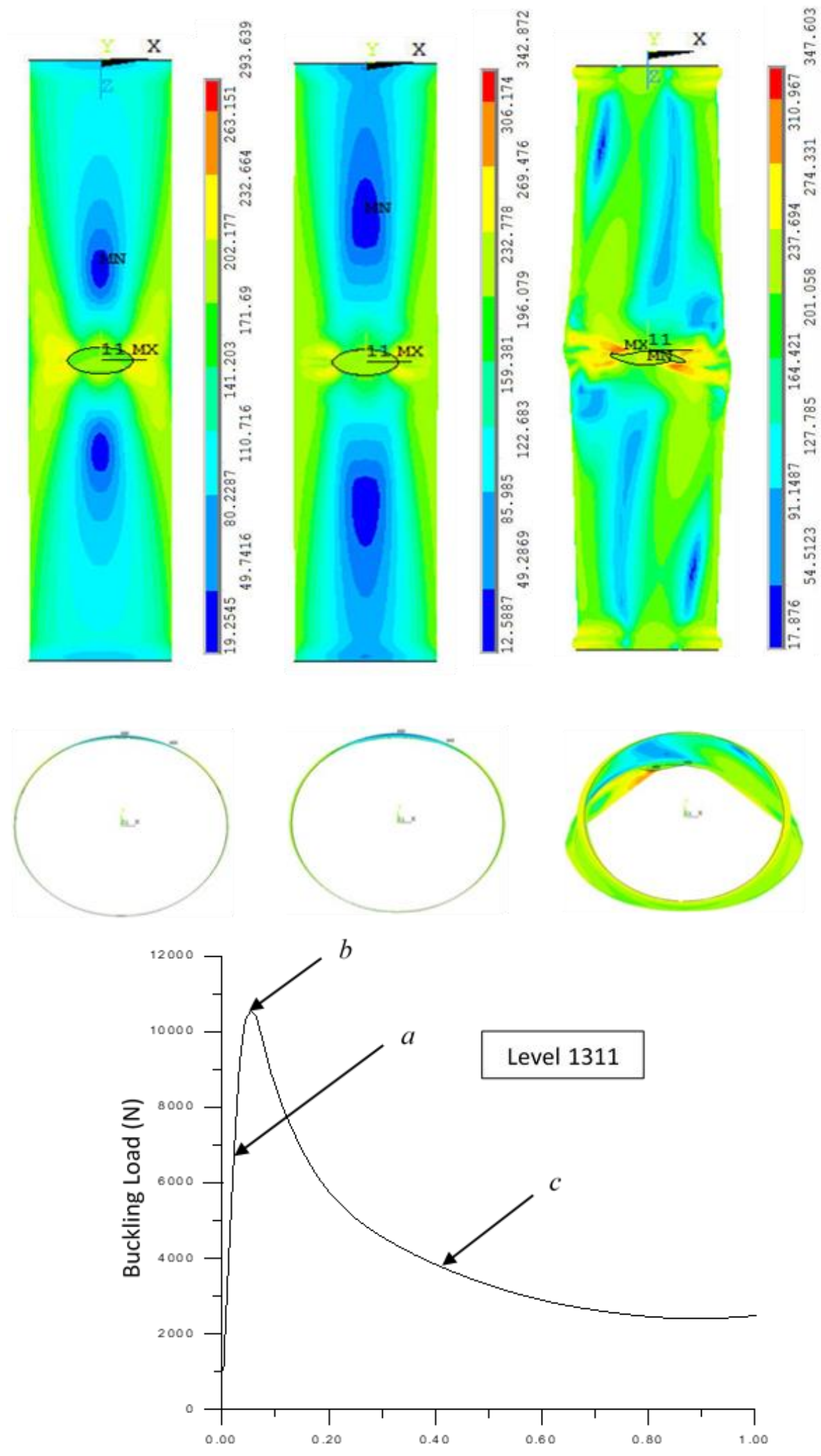

Figure 4. Load vs. end shortening, shell distortion and von Mises stress contours at different loading steps of the specimen level 1311. 

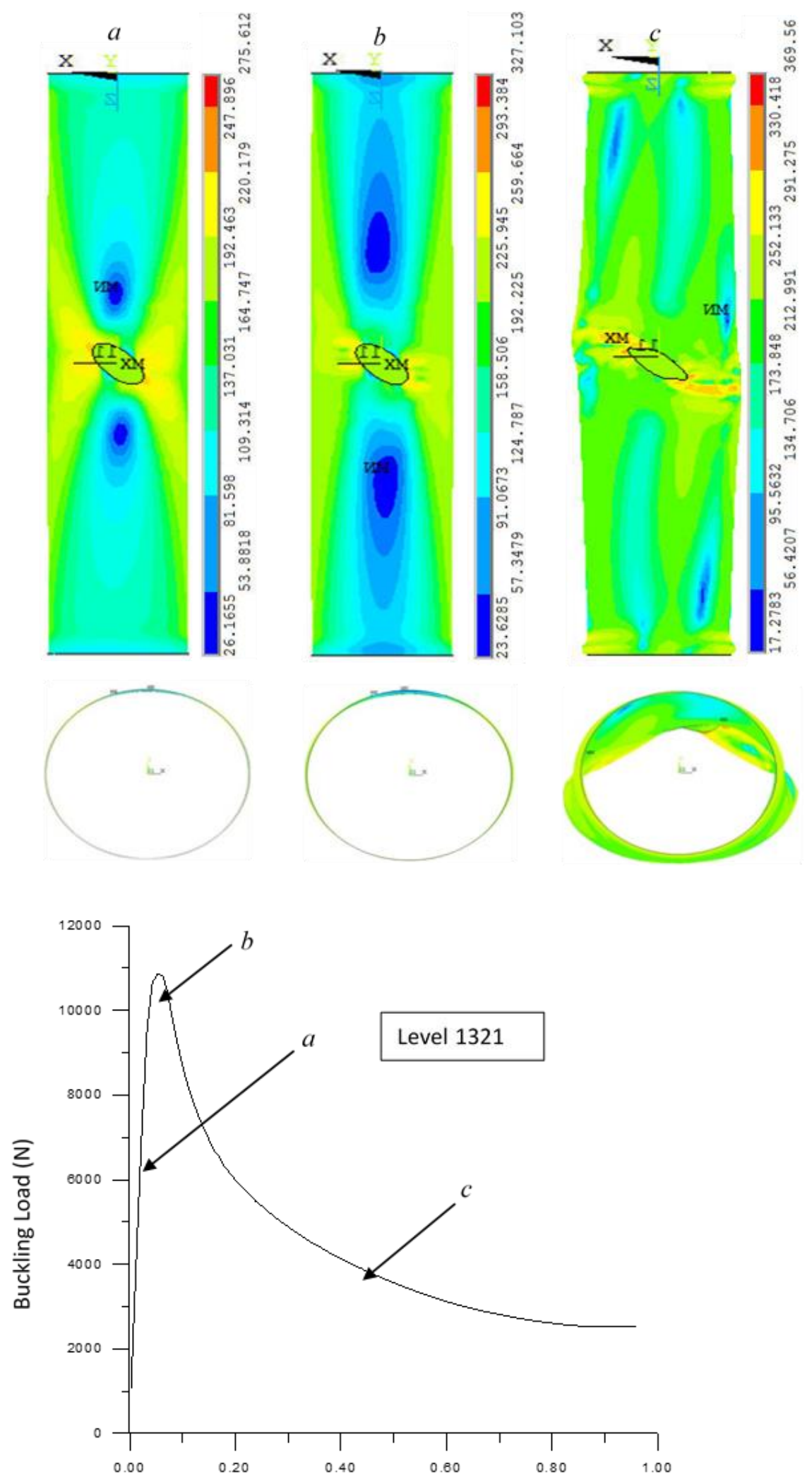

Figure 5. Load vs end shortening, shell distortion and von Mises stress contours at different loading steps of the specimen level 1321. 


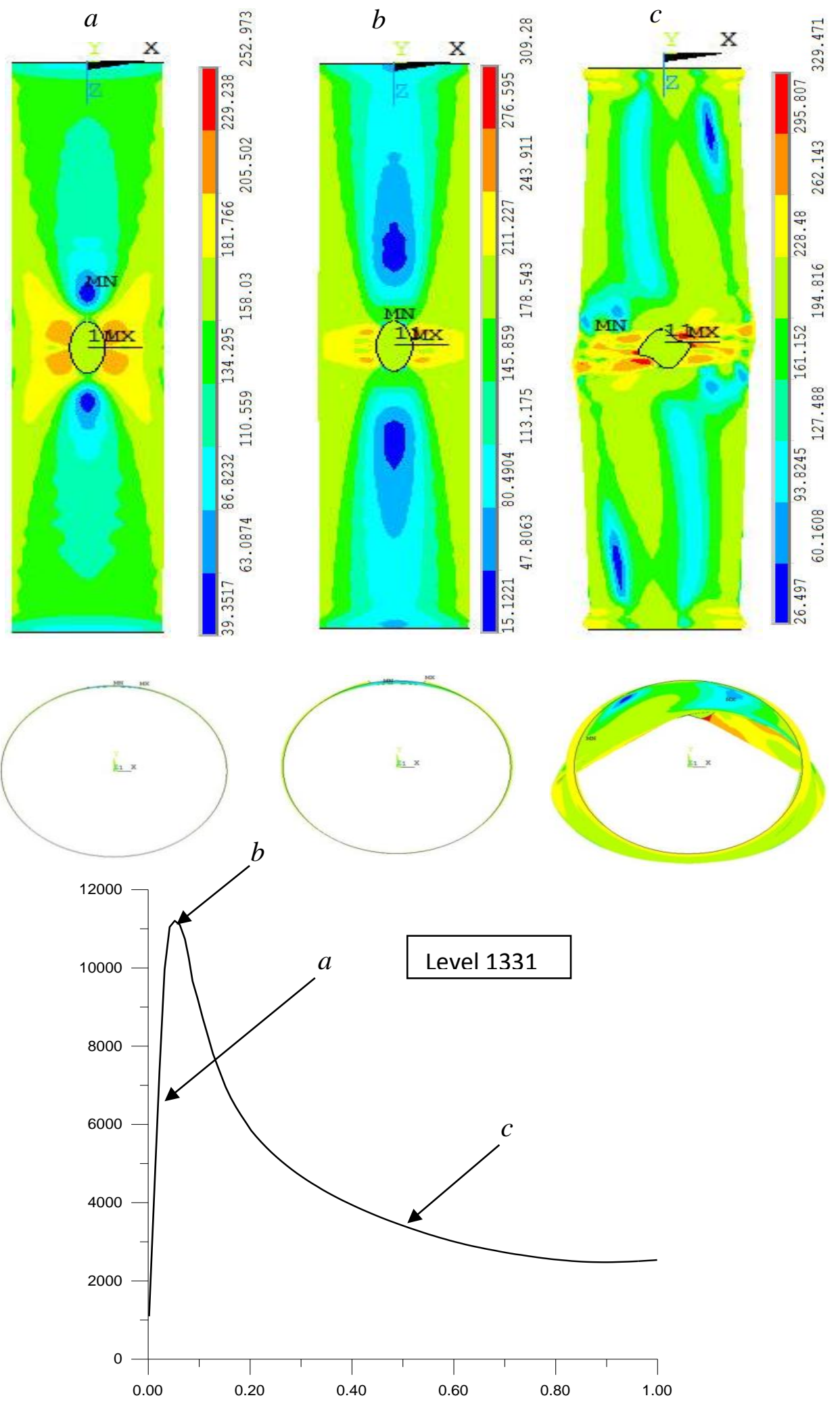

Figure 6. Load vs end shortening, shell distortion and von Mises stress contours at different loading steps of the specimen level 1331. 


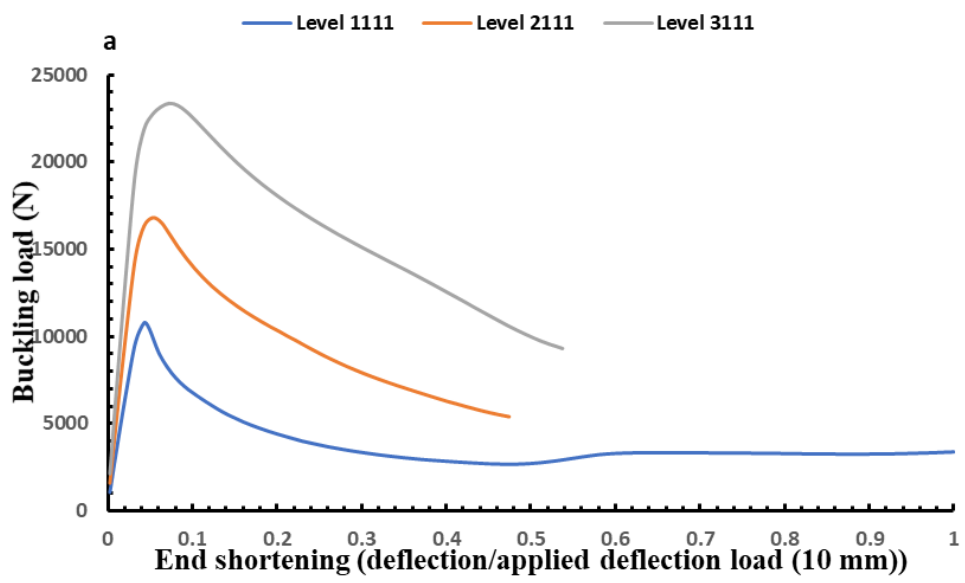

(a)

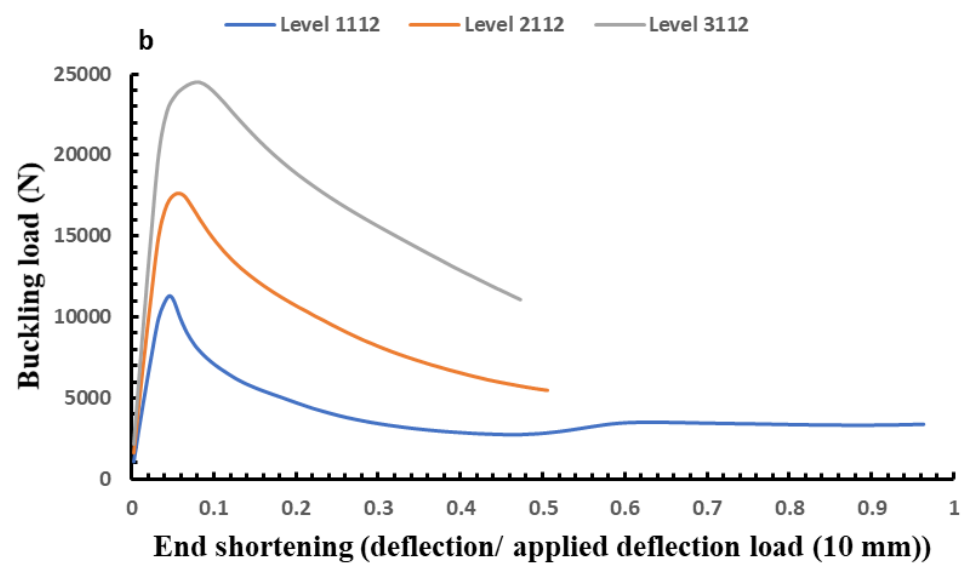

(b)

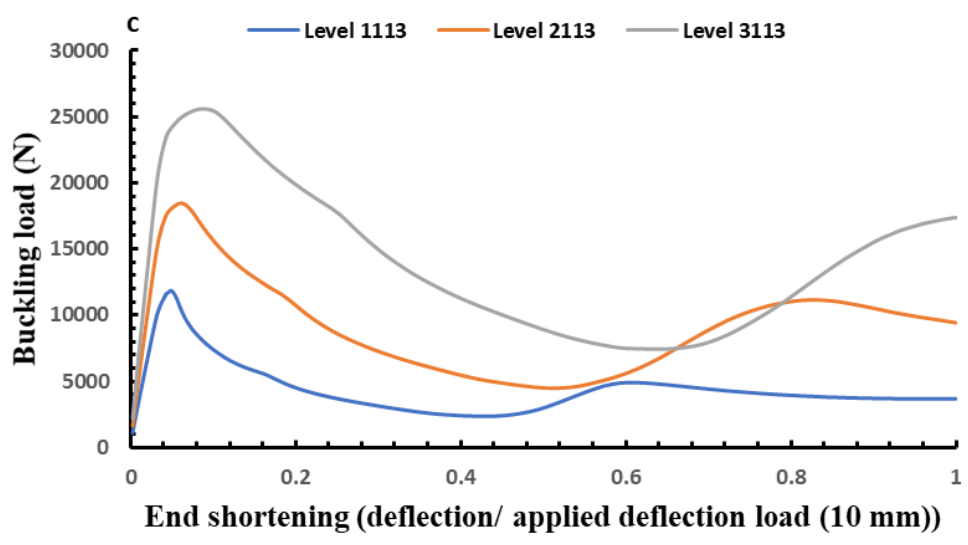

(c)

Figure 7. Load vs end shortening showing the effect of thickness change for a cylindrical shell with elliptical cutout 


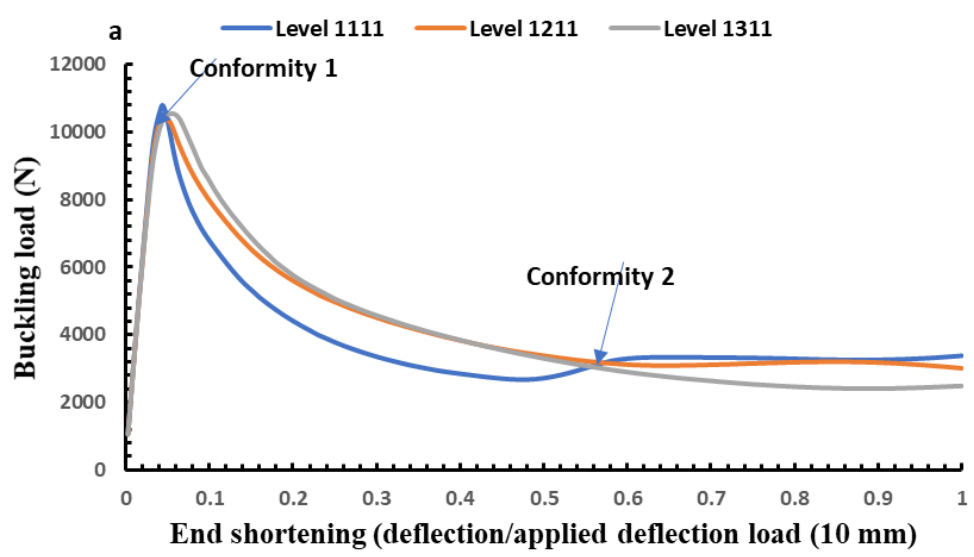

(a)

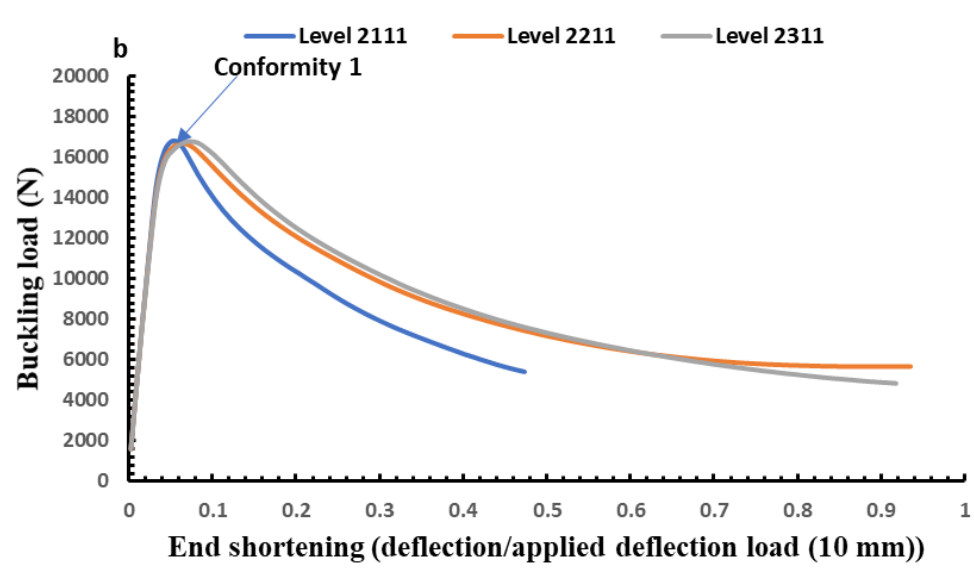

(b)

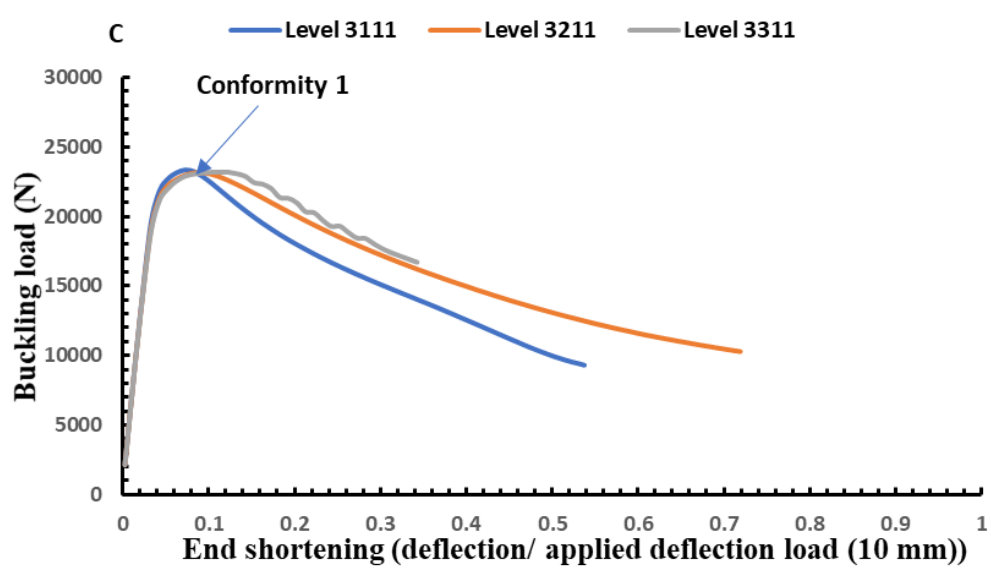

(c)

Figure 8. Load vs end shortening showing the effect of changing cutout position on buckling behaviour of a cylindrical shell with elliptical cutout.

\section{EMPIRICAL-NUMERICAL EQUATION}

In this section, an empirical numerical based formula is presented for the critical buckling load of a cylindrical shell having an elliptical cut-out. Such a formula is useful for a fast design because a proper value of the buckling load can be predicted efficiently. Based 
on the available numerical data through simulation study carried out in this work, a nonlinear regression fitting method using XLSTAT software was used. The empirical formula takes into account the dependence of typical design parameters: cylinder $(D / t)$, cut-out position $\left(L_{c} / L\right)$, cut-out orientation (theta), and cut-out size $(b / a)$. The general equation used for the evaluation of the buckling load is:

Buckling load

$(\mathrm{N})=\mathrm{A}+\mathrm{B}^{*} \mathrm{X}_{1}+\mathrm{C}^{*} \mathrm{X}_{2}+\mathrm{D}^{*} \mathrm{X}_{3}+\mathrm{E}^{*} \mathrm{X}_{4}+\mathrm{F}^{*} \mathrm{X}_{1}^{2}+\mathrm{G}^{*} \mathrm{X}_{2}^{2}+\mathrm{H}^{*} \mathrm{X}_{3}^{2}+\mathrm{I}^{*} \mathrm{X}_{4}^{2}+\mathrm{J}^{*} \mathrm{X}_{1} * \mathrm{X}_{2}$

$+\mathrm{K}^{*} \mathrm{X}_{1} * \mathrm{X}_{3}+\mathrm{L} * \mathrm{X}_{1} * \mathrm{X}_{4}+\mathrm{M} * \mathrm{X}_{2} * \mathrm{X}_{3}+\mathrm{N} * \mathrm{X}_{2} * \mathrm{X}_{4}+\mathrm{O} * \mathrm{X}_{3} * \mathrm{X}_{4}$

Where $\mathrm{X}_{1}=\mathrm{D} / \mathrm{t}, \mathrm{X}_{2}=\mathrm{L}_{\mathrm{c}} / \mathrm{L}, \mathrm{X}_{3}=$ theta (in degrees), $\mathrm{X}_{4}=\mathrm{b} / \mathrm{a}$. The coefficients $A, B, C$, $\ldots$ are evaluated using the nonlinear regression method. The exact form of the resulting equation is in Eq. (2). In the parameters range considered in this study, the maximal difference between numerical simulations and the formulas is below $4.09 \%$.

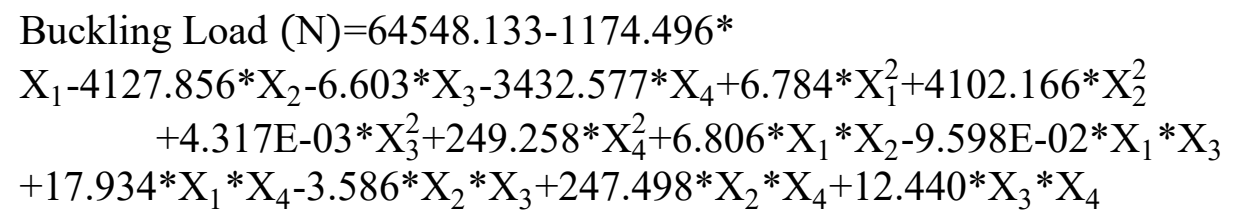

\section{CONCLUSION}

A three-dimensional nonlinear numerical analysis using the finite element method was carried out to explore the effect of changing elliptical cut-out design parameters on both load-bearing capacity and buckling behaviour of steel cylindrical shell subjected to compressive loading. The design parameters include changing $\mathrm{D} / \mathrm{t}$ ratio, cut-out location $\mathrm{L}_{\mathrm{c}}$, cut-out orientation $\theta$, and cut-out size b/a. The study comes out with the following conclusions:

i. The cut-out position in a cylindrical shell affects its buckling load capacity in which changing cut-out location from mid-height of the cylindrical shell towards a fixed edge increased the buckling load. In consequence, longer shells are sensitive to cut-out location.

ii. Increasing shell thickness has a positive effect on shell buckling behaviour since the buckling load was increased due to thickness increasing.

iii. Increasing cut-out orientation increases buckling load too.

iv. Increasing cut-out size decreased buckling load capacity.

v. A regression formula for computing buckling load for a cylindrical shell with elliptical cut-out was achieved. The formula considers four design parameters.

\section{REFERENCES}

[1] Ifayefunmi O, Blachut J. Imperfection sensitivity: A review of buckling behaviour of cones, cylinders and domes. Journal of Pressure Vessel Technology. Epub ahead of print 2018. DOI: 10.1115/1.4039695.

[2] Hart-Smith LJ. Buckling of thin cylindrical shells under uniform axial compression. International Journal of Mechanical Sciences 1970; 299-313.

[3] Sheinmant I, Simitsess GJ. Buckling and postbuckling of imperfect cylindrical shells under axial compression. Journal of Computers \& Structures 1983; 17: 277285. 
[4] Stasiewicz P. Analytical and experimental studies of stability of cylindrical shells with a cut-out. Mechanics and Mechanical Engineering 2013; 17: 167-176.

[5] Eggwertz S, Samuelson LÅ. Design of shell structures with openings subjected to buckling. Journal of Constructional Steel Research 1991; 18: 155-163.

[6] Lykhachova O. Numerical Simulation of Axially Compressed Cylindrical Shells with Circular Cutouts. 2016; 20: 309-320.

[7] Zou RD, Foster CG. Simple solution for buckling of orthotropic circular cylindrical shells. Thin-Walled Structures 1995; 22: 143-158.

[8] Jullien JF and Limam A. Effect of openings on the buckling of cylindrical shells subjected to axial compression. Thin-Walled Struct 1998; 31: 187-202.

[9] Ifayefunmi O, Fadzullah SHSM. Buckling behaviour of imperfect axially compressed cylinder with an axial crack. International Journal of Automotive and Mechanical Engineering 2017; 14: 3837-3848.

[10] Estekanchi HE, Vafai A. On the buckling of cylindrical shells with through cracks under axial load. Thin-Walled Structures 1999; 35: 255-274.

[11] Mandal P, Calladine CR. Buckling of thin cylindrical shells under axial compression. International Journal of Solids and Structures 2000; 37: 4509-4525.

[12] Holst JMFG, Rotter JM. Axially compressed cylindrical shells with local settlement. Thin-Walled Structures 2005; 43: 811-825.

[13] Hilburger MW, Starnes JH. Buckling behaviour of compression-loaded composite cylindrical shells with reinforced cutouts. International Journal of Non-Linear Mechanics 2005; 40: 1005-1021.

[14] Taheri-Behrooz F, Omidi M, Shokrieh MM. Experimental and numerical investigation of buckling behaviour of composite cylinders with cutout. ThinWalled Structures 2017; 116: 136-144.

[15] Han H, Cheng J, Taheri F, et al. Numerical and experimental investigations of the response of aluminum cylinders with a cutout subject to axial compression. ThinWalled Structures 2006; 44: 254-270.

[16] Shariati M, Rokhi MM. Numerical and experimental investigations on buckling of steel cylindrical shells with elliptical cutout subject to axial compression. ThinWalled Structures 2008; 46: 1251-1261.

[17] Ghanbari Ghazijahani T, Jiao H, Holloway D. Structural behaviour of shells with different cutouts under compression: An experimental study. Journal of Constructional Steel Research 2015; 105: 129-137.

[18] Celebi M, Gürdal Z, Tatting B, et al. Effects of Size and Location of a Circular Cutout on Buckling and Failure of a Cylindrical Shell in Bending. In: 58th AIAA/ASCE/AHS/ASC Structures, Structural Dynamics, and Materials Conference. 2017. Epub ahead of print 2017. DOI: 10.2514/6.2017-0433.

[19] ANSYS user's manual, ANSYS Inc. USA; 2003.

[20] Shariati M. Study on buckling of steel cylindrical shells with an elliptical cutout under combined loading. Journal of Computational and Applied Research in Mechanical Engineering 2013; 13-25.

[21] Shariati M, Rokhi MM . Numerical Analysis Using the Finite Element Method. International Journal of Steel Structures 2010; 10: 193-205. 